\title{
The Development of Central Kitchen Logistics Management System in the University
}

\author{
Quanzhou Huang \\ School of Computer Science, Xi'an Shiyou University, Xi'an, Shaanxi, 710065, China \\ qzhuang@xsyu.edu.cn
}

Keywords: Center kitchen; Logistics management; Food orders; Distribution management

\begin{abstract}
This paper introduces the concept of central kitchen, analyses the shortcomings of the traditional management model, and points out the advantages of the center kitchen. This is a new management model, central kitchen is responsible for the procurement, production and distribution of food, restaurants order foods from the central kitchen, product foods no longer, but merely sell foods. It briefly discusses the main problems involved in the central kitchen management system, and uses object-oriented method and UML to analyse, design and implement the system. It gives the results of requirements analysis, software structure design and the main database design, also gives the system development plan and task workflow.
\end{abstract}

\section{Introduction}

In the unversity, there are a number of restaurants, the restaurants provide food services for students and teachers. There are many large devices, many foods and many employees. Foods from purchasing, processing, to sales must pass many links and equipment, the work is complex, labor intensity is big. Each restaurant almost has the same equipment, workflow and food production, duplication and serious resource waste and low efficiency.

In order to meet the needs of modern management, enterprises need to improve the workflow, integrate resources, improve the production efficiency, reduce waste[1]. Based on this, we put forward the concept of the center kitchen.

The center kitchen is to set up a modern food production base, equipped with complete environmental protection equipment, food processing equipment and skilled technical workers. From Ordering of raw materials, food production to food sells, the center kitchen carry out unified management. The restaurants product foods no longer, but merely sell foods. Restaurants order foods from the center, the center kitchen products and distribute foods. This is a new type of production and management mode.

Compared to traditional model, the new model has many advantages. It conforms to the modern management mode, save resources, improve the working efficiency, avoid the repetitive construction and investment, and also facilitate focused on quality management and supervision[2,8]. Central kitchen implements five unity, including: unified purchase, unified order, unified distribution, unified regulation and settlement. Entralized feeding is more conducive to the school food hygiene safety[7,8].

Based on information technology and workflow technology, this paper mainly discusses the key technology of central kitchen logistics management system and the system development method.

\section{Systems Analysis}

Requirements Analysis. System users include central kitchen users and restaurant users.

Central kitchen users need for the logistics management system are as follows by survey: users information management ,foods information management ,restaurant information management,orders inforamtion mangement,distribution information management,financial information management, inforamtion query and so on. The end of every month will do financial statistics and accounting for all restaurants according to the orders, and produces various types report forms. 
Restaurant users as the client need for the logistics management system are as follows by survey: browse foods,choose foods ,produce orders,modify orders, financial information management, information query and so on.

System use case diagram. Restaurant use case diagram, as shown in Fig. 1.

Central kitchen users use case diagram, as shown in Fig.2.

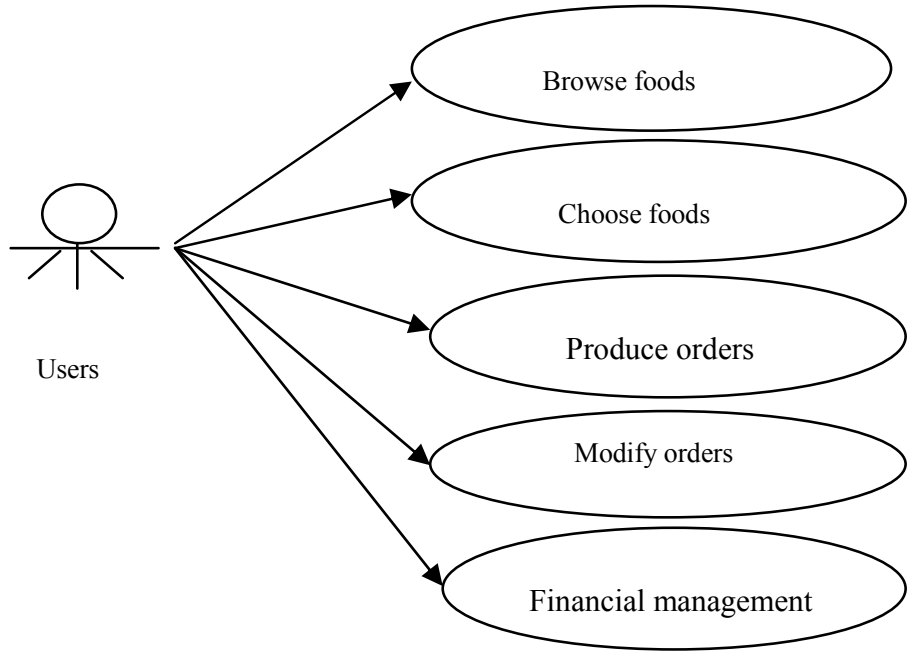

Figue 1. Restaurant users use case diagram

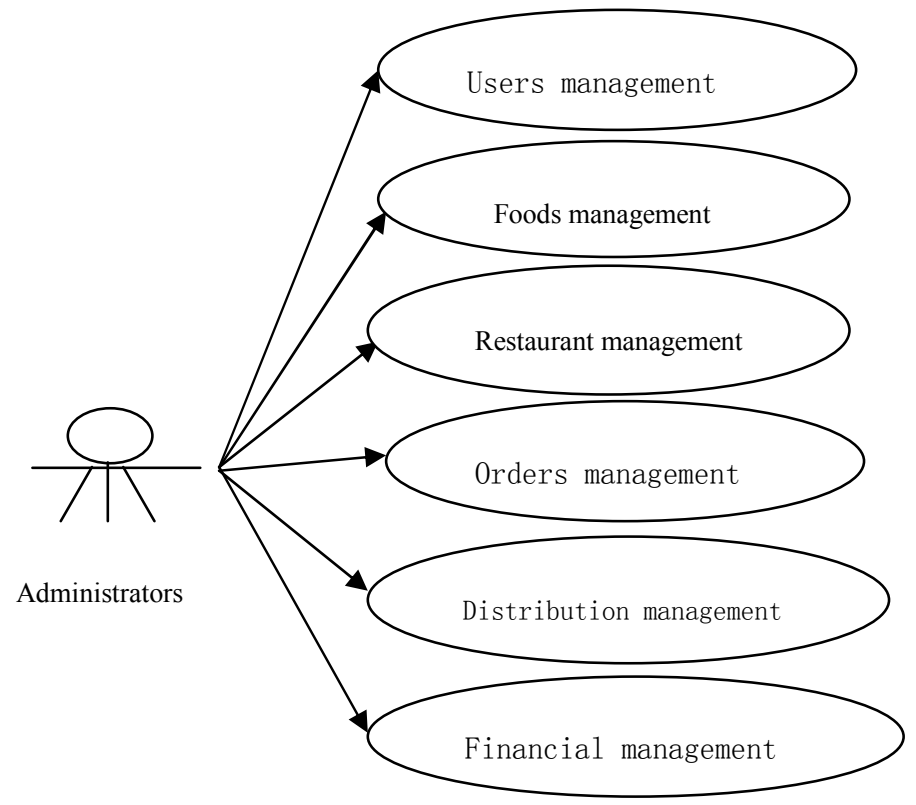

Figure 2. Central kitchen users use case diagram

\section{System Work Flow.}

(1) First users login system according to password.

(2) Restaurant users browse foods list, and choose foods

(3) The orderer fill in the orders form,including various information about the orders.

(4) The orderer may modify the orders before submission.

(5) The orderer formally submits the orders.

(6) Central kitchen users may view the orders and send the orders to production department and distribution department.

(7) Central kitchen users may sum the orders according to the food types, produce summary orders table every day.

(8) Deliveryman delivery goods to the restaurant on time according to the order.

(9) Deliveryman may fill in the delivery information. 
(10) The last orders are set to completed status.

(11) The end of every month will do financial statistics and accounting for all restaurants according to the orders.

\section{Systems Design}

System Overall Architecture. The system is developed in $\mathrm{B} / \mathrm{S}$ mode. According to the function, the system is divided into two modules: restaurant module as front desk and central kitchen management module as background. Orders management and financial amagement are the key of the system. System software architecture diagram is shown in Fig. 3.

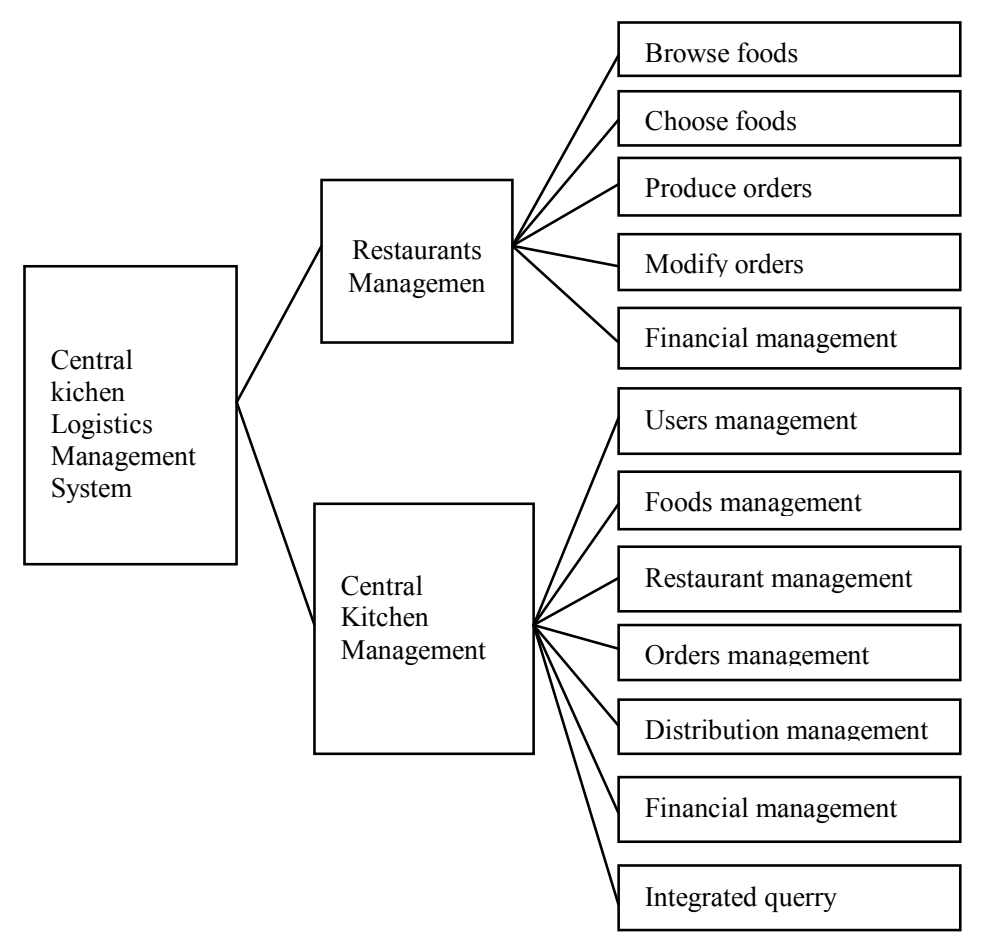

Figue3. The software structure diagram

The Main Database Design. Database design is one of the key in the system design, it must comply with the principle of database design[3,4,9]. Each table has its own primary and foreign keys. According to the results of system analysis, the following main database tables are designed.

Users information table

This table is used to store users ' data, including user name, password, and other information. Foods information table

This table is used to store basic foods information, including food code, name, units,price, function etc.

Restaurant information table

This table is used to store the restaurants information, mainly including restaurant code, name, address etc.

Order and distribution information table

This table stores specific information of orders and distribution information, including order code, date,restaurant code, orderer, order time, delivery time,price, total price,distribution time, diliveryman order status etc.

Order details table

This table stores specific information of each order foods details,including order code,food code,amount, price, total price etc. 


\section{System Implementation}

System network structure is shown in Fig. 4. The central kitchen, restauants and data center(database server) link together by the campus network. All the data is stored in database server of the data center for sharing. Users use the logistics management software to complete all kinds of tasks.

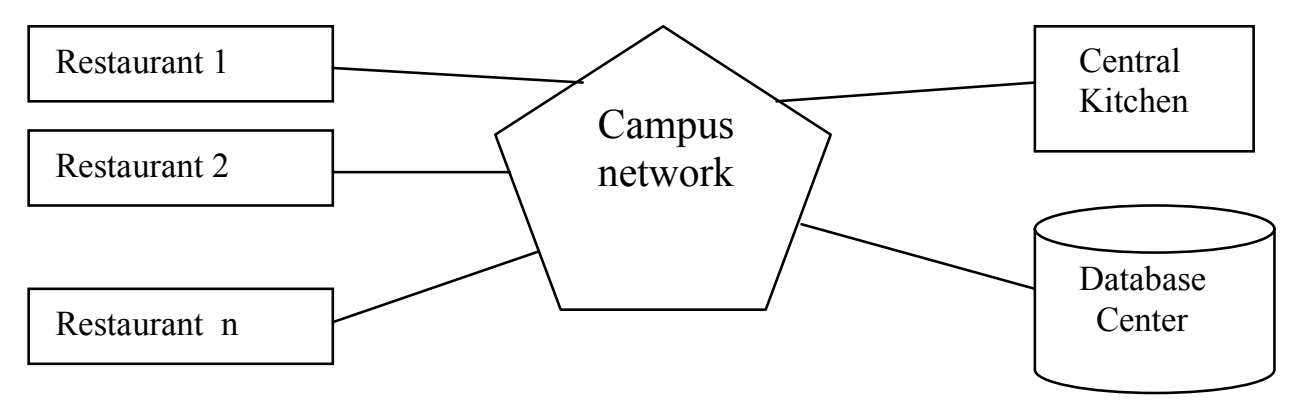

Figure 4. System network sturcture diagram

The system is based on a Java platform development, it uses JSP programming technology, uses SQL server database. Using object-oriented method and UML to analysis, design and modeling, the software system has a good structure and extensibility, and it has a friendly interface, easy to operate[5,6]. After careful testing, it has reached the design goals.

\section{Summary}

This paper put forward the concept of the central kitchen, analyses the shortcomings of the traditional management model, and points out the advantages of the center kitchen. This is a new management model. It briefly discusses the main problems involved in the central kitchen management system, and use object-oriented method and UML to analyse, design and implement the system. Compared with the traditional restaurant management model, the new managememt model and office automation software based on workflow technology will bring many advantages to the enterprise, not only save the cost, but also improves the production efficiency[7,8].

\section{References}

[1] G.H. Shen: Logistics \& Material Handling, Vol. 12(2017) No. 3, P.69. (In Chinese)

[2] Y.J. Song: Modern Business Trade Industry, Vol. 3(2014) No. 1, P.181. (In Chinese)

[3] L.M. Mu and G.F. Liu: Computer Applications and Software, Vol. 27(2010) No. 8, P.79. (In Chinese)

[4] H.J. Zhou: Jilin University, Vol. 23(2009) No. 2, P.35-38. (In Chinese)

[5] W.L. Su and Z.Y. Zhang: Computer Knowledge and Technology, Vol. 8(2012) No. 16, P3869. (In Chinese)

[6] Information on http://www.docin.com/p-1467558646.html

[7] Information on https://wenku.baidu.com/view/d01b3658804d2b160b4ec03e.html

[8] R.S. Pressman: Software Engineering: A Practitioner's Approach (Mechanical Industry Press, China 2010). (In Chinese)

[9] I. Jacobson: The Unified Software Development Process (Mechanical Industry Press, China 2012). (In Chinese) 